\title{
SEDUNIT PROJECT: STUDY OF THE ACCUMULATION, EROSION AND SEDIMENT TRANSPORT OF COHESIVE SOLIDS IN COMBINED SEWER SYSTEMS
}

\author{
JOSE ANTA, JOAQUÍN SUÁREZ, ALFREDO JÁCOME, MANUEL REGUEIRO-PICALLO, \\ JERÓNIMO PUERTAS, JUAN NAVES \& MONTSERRAT RECAREY \\ Universidade da Coruña, Water and Environmental Engineering Group (GEAMA), A Coruña, Spain
}

\begin{abstract}
The SEDUNIT Project is a Spanish National Research focused on the study of the sediment transport in combined sewer systems. The main objective of this study is to advance in the understanding of the sediment accumulation and erosion processes in combined sewer systems and the optimization of the operation and maintenance practices in sewer networks. The research is divided into three tasks corresponding to different scales in order to approach the objectives of the Project: laboratory tests, field work and numerical modelling. A flume test facility is utilized for the laboratory scale. In this facility, a series of experiments are performed in order to study the accumulation and erosion processes. For the second task, a real combined sewer is being monitored in order to validate laboratory results. The sediment properties and the volume of the accumulated solids in the sewer are the main analysed parameters. The last task consists in a review of the existing sediment transport models and their applicability to assess how parameters such as the cohesion of solids affect the resuspension processes and how they should be included in the existing models.

Keywords: combined sewer, flume test, sediment transport, sewer dynamics, sewer processes, sewer sediments, urban drainage, wastewater pipeline.
\end{abstract}

\section{INTRODUCTION}

This Project deals with new sustainable management practices for urban drainage systems. The actual policies must integrate social and economic sustainability criteria and must be more resilient against climate change. For that, strategies based on Low Impact Development (LID) or Water Sensitivity Urban Design (WSUD) should be considered [1]. The purpose of this Project is to understand the in-sewer processes, particularly the accumulation and erosion of bed deposits. In combined sewer systems, the deposits of sediments reduce the hydraulic capacity of the conduits (increasing flooding and pollution spill risks), increase odour and gas production (methane and sulphide mainly) and operating problems. Thus, the first flush after a long dry period mobilize a huge amount of solids which can damage pumping stations at Wastewater Treatment Plants (WWTP) [2]. To avoid or minimize such problems is essential to have review existing sewer design criteria and optimize the operation and maintenance practices accounting for sediment accumulation and erosion processes.

Past decades studies were focused in measurements in real sewers or studies of sewer hydraulics in full scale models in order to approach the knowledge of sediment accumulation and transport processes in sewers [3]. Furthermore, most of sediment transport formulas for sewer systems have been developed from studies with non-cohesive and uniform sediments [4]. Current studies are focused on understanding the sediment cohesion, with a variety of particle sizes, and integrating other phenomena such as organic matter transformations [5][8]. Thus, working with real wastewater in the most controlled conditions is crucial (in terms of hydraulic and pollution aspects). In the SEDUNIT Project the above conditions are met. The planned activities and the proposed methodologies guarantee an advance in the state of knowledge. A key aspect that ensures obtaining new results is the availability of a Scientific Platform for Pipe flow measurements with real wastewater. This platform allows to work in 
very close to reality conditions but with a capacity to monitor, measure and characterize water and sediment flows and sediment that are not found in a field campaign inside a sewer system.

\section{RESEARCH BACKGROUND}

The SEDUNIT Project is being developed together with two more Projects called OvalPipe I and II. These projects are headed by a local company that is developing a new plastic eggshaped pipe system with the aim of improving the sewer pipelines efficiency. For that, the OvalPipe I (from 2013 to 2015) was the first approach in order to define and to test the hydraulic and mechanical characteristics. The hydraulic research was performed in a metallic egg-shaped prototype placed at the R\&D Centre of Technological Innovation in Building and Civil Engineering (CITEEC) of the University of a Coruña. The results of a series of experiments were numerically modelled and compared with an equivalent-area circular pipe [9]. As a part of the OvalPipe I Project, a flume test facility was also built inside the WWTP at A Coruña to compare the self-cleaning efficiency between a $315 \mathrm{~mm}$ circular pipe and a plastic egg-shaped prototype with real wastewater conditions [10]. This first plastic prototype was made with an injection molding process and its weaknesses were the continuity of the geometry and the pipe joints. New building processes are being developing in the OvalPipe II Project (from 2016 to 2018), which is focused on achieving a better fabrication process of pipes and joints between egg-shaped pipes and also between egg-shaped and circular pipes. The resulting prototypes are planned to be also tested in the flume test facility.

In this work we present the experimental campaigns at the WWTP experimental flume focused in studying the accumulation and erosion processes as a part of the SEDUNIT Project.

\section{LABORATORY CAMPAIGN}

The laboratory approach to the sediment transport of cohesive solids was performed in a flume test facility fed with real wastewater (Fig. 1). This flume is placed at the pretreatment facility of the WWTP at A Coruña (600,000 inhabitants). Thus, wastewater is driven through a pumping system to an inlet chamber that feeds the flume. The metallic bench presents a length of $10 \mathrm{~m}$, a width of $0.8 \mathrm{~m}$ and an adjustable slope from $0 \%$ to $2 \%$. Over this bench, two configurations of sewer pipes were placed. In the first campaign, a circular $315 \mathrm{~mm}$ PVC pipe was set together with an equivalent area egg-shaped pipe. In the second series of tests, two circular PVC pipes of 315 and $400 \mathrm{~mm}$ outer diameters were studied. Downstream, a tailgate is automatically controlled in order to fix boundary conditions.

The flume is equipped with different hydraulic and wastewater load sensors. The wastewater characterization at the inlet chamber was monitored with turbidity (SOLITAX) and UV absorption (UVAS) probes. The signal of these sensors was calibrated with the

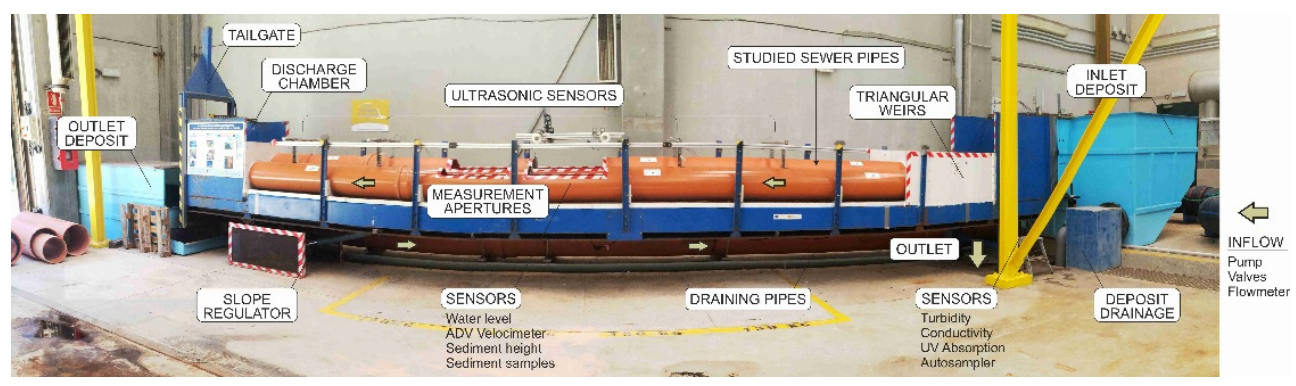

Figure 1: General view of the flume test facility. 


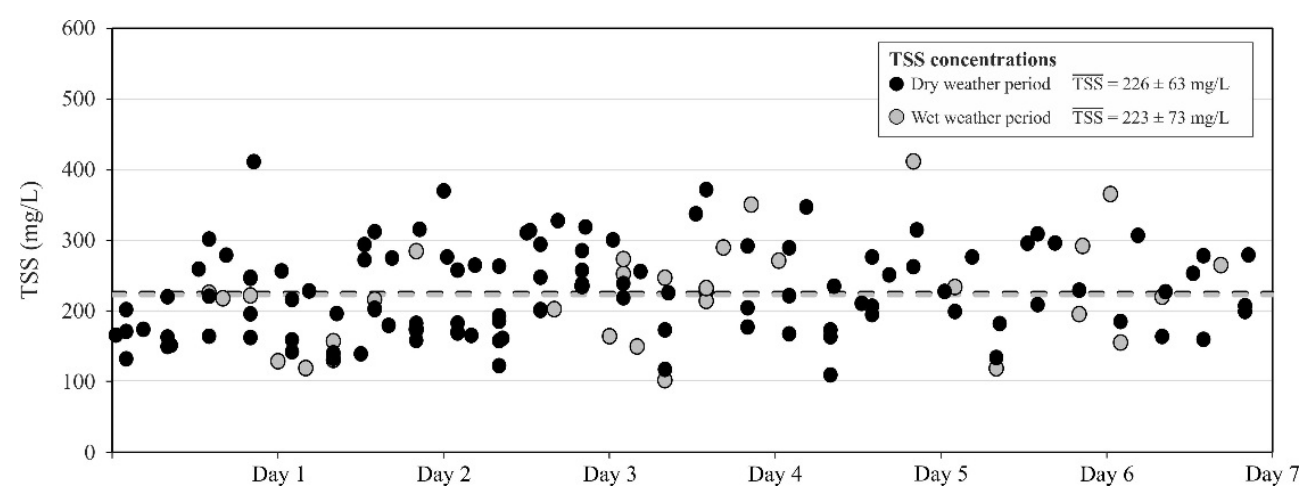

Figure 2: Weekly variation of TSS input to the flume according to the weather conditions.

analysis of the Total Suspended Solids (TSS) and the Chemical Oxygen Demand (COD) from wastewater samples taken every 6 hours with an autosampler. The resulting average TSS and COD concentrations were $224 \pm 65 \mathrm{mg} / \mathrm{L}$ and $414 \pm 80 \mathrm{mg} / \mathrm{L}$ respectively. The TSS analysis from inlet samples showed a smooth daily pattern and a negligible influence of the dry-wet weather conditions in the TSS loads (Fig. 2).

Two experimental procedures were designed during the laboratory campaign. On one hand, short and long term accumulation tests were performed to analyze the sediment accumulation under different hydraulic conditions: slopes ranges of $1 \%$, $2 \%$ and $5 \%$ and flowrates ranging from $3 \mathrm{~L} / \mathrm{s}$ to $4.6 \mathrm{~L} / \mathrm{s}$. In the cases where the deposition occurred, the focus was on how the hydrodynamics, the bed deposit heights, and the physicochemical properties of sediments evolved. On the other hand, erosion tests were executed with the same initial conditions but different consolidation times for the bed deposits after increasing the flowrate in each pipe up to $12 \mathrm{~L} / \mathrm{s}$. The objective of the erosion tests was to observe the influence of the biological transformations of the sediments in sediment erosion processes. A detailed description of the experimental procedures and conditions can be consulted in RegueiroPicallo et al. [10], [11].

The sediment deposits were daily recorded. For that, the flowrate was stopped and the pipes were carefully emptied to avoid the bed erosion. Once the pipelines were drained, ultrasonic sensors and imaging techniques were applied to obtain the deposit heights [10], [11]. Furthermore, manual samples of the bed deposits were grabbed from the same measurement apertures for the physicochemical analysis [12]-[14]. Fig. 3 presents the a boxwhisker plot with the main relevant sediment properties recorded in the tests: sediment density and mean diameter $\left(\mathrm{d}_{50}\right)$, Total Solids (TS), ratio between Total and Volatile Solids (TS/VS), COD and Oxygen Uptake Rate (OUR).

In the sediment accumulation tests, bed deposits occurred with mean flow velocities below $0.26 \mathrm{~m} / \mathrm{s}$ in the $315 \mathrm{~mm}$ and $400 \mathrm{~mm}$ circular pipes while no presence of deposit were observed in the egg-shaped pipe (Fig. 4). Growth rates between 1.4 and $3.8 \mathrm{~mm} / \mathrm{d}$ were obtained from the daily sediment height recordings in the circular geometries, depending on the mixing conditions in the head tank in order to resuspend the particles (see RegueiroPicallo et al. [10]). A value of $2.85 \mathrm{~mm} / \mathrm{d}$ was obtained in past studies with similar conditions in a $300 \mathrm{~mm}$ inner diameter pipe [15].

Besides the hydraulics and the solid loads conditions, the bed deposits accumulation also depends on the wastewater hydrodynamics. The progressively growth of sediments in the circular pipes slightly increases the centreline velocity profiles, which were measured with a 
Nortek Vectrino(C Acoustic Doppler Velocimeter. Fig. 5 shows the log-scale velocity acceleration for a 7 days accumulation test whereas the Reynolds shear stress remain quasiconstant. In this case, the shear stress is not influenced by the sediment accumulation and a steady deposition ratio can therefore be expected.

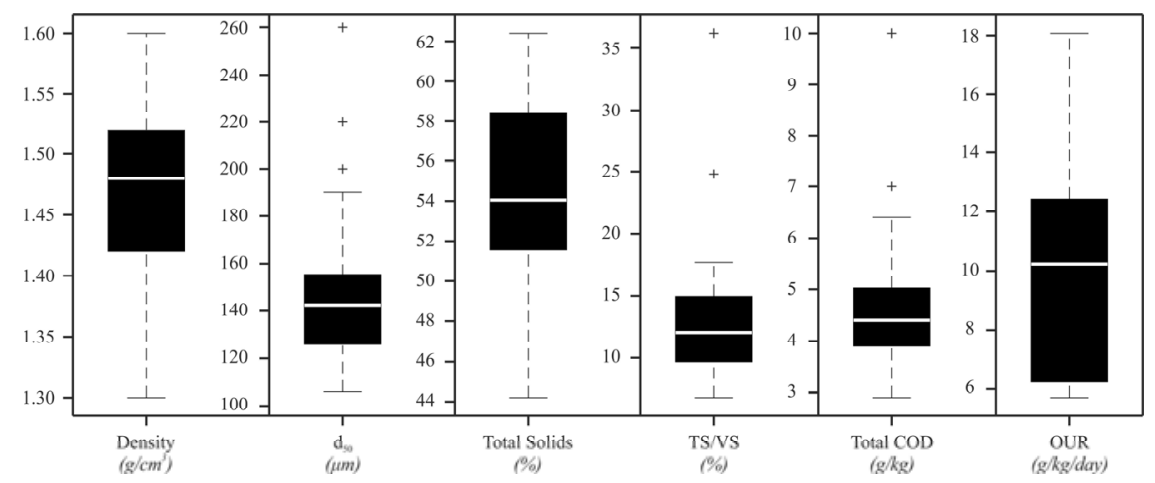

Figure 3: Physicochemical analysis of the sediment samples collected in the pipe inverts.

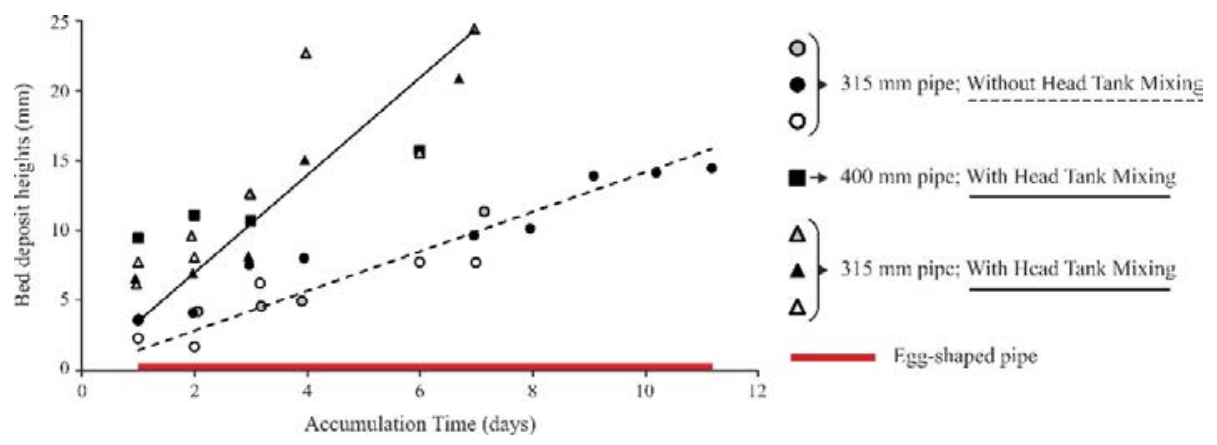

Figure 4: Daily accumulation growth in the circular and egg-shaped pipes with different head tank mixing conditions. (Source: Regueiro-Picallo et al. [10], [11].)

(a)

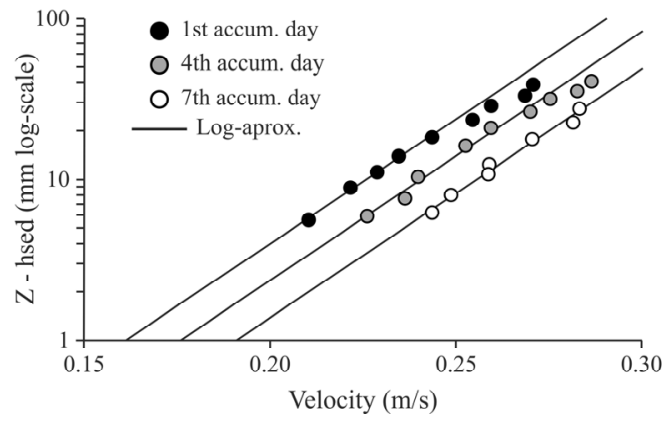

(b)

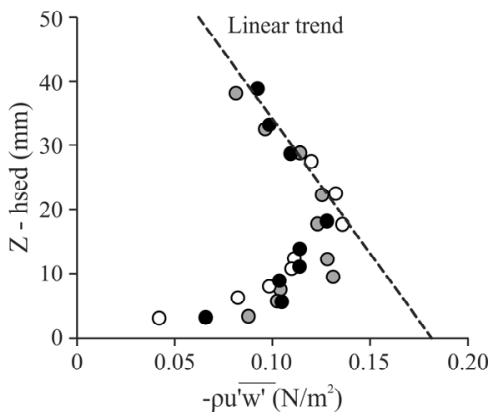

Figure 5: Evolution of centreline velocity profiles: (a) and Reynolds shear stress; (b) in a 7 days accumulation test. (Source: Adapted from Regueiro-Picallo [10], [11].) 
(a)

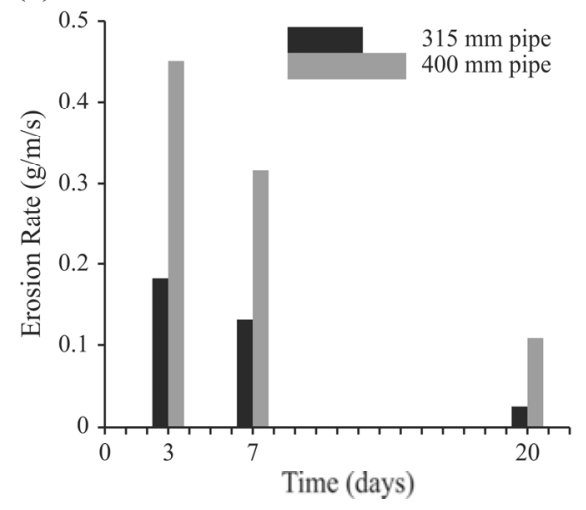

(b)

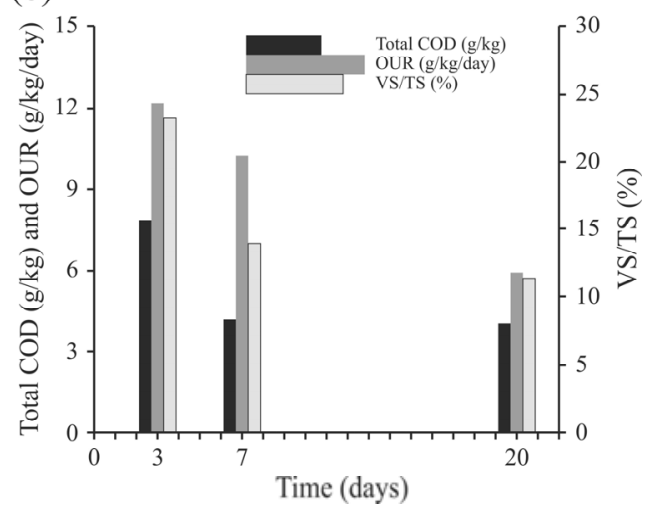

Figure 6: Evolution of the erosion rate: (a) and the organic matter parameters of the initial bed deposits; (b) for different consolidation periods. (Source: Regueiro-Picallo et al. [11].)

In the erosion tests, although the same inlet conditions different erosion rates were obtained due to the sediment consolidation time applied (3, 7 and 20 days), the erosion rates were calculated as the difference between the initial and the final bed deposits. For that, a photogrammetric technique called Structure from Motion (SFM) was utilised [11]. The initial sediment heights were set to an averaged value of $7.3 \mathrm{~mm}$ and $14.3 \mathrm{~mm}$ in the 315 and 400 $\mathrm{mm}$ pipe respectively. At the end of these erosion tests, it was observed that the eroded mass decreased as the sediment accumulation time in the pipe invert increases (Fig. 6(a)). This trend was also connected with the decrease of the organic matter indicators of the sediment samples; VS/TS, COD and OUR taken before the tests (Fig. 6(b)). Therefore, these relationships show that the bed deposits erodibility is affected by the biological activity of the sediment. The decrease of the organic content concentration and the sample degradation implies a higher cohesiveness of the bed deposits in long-term deposition. In contrast, 'fresh' sediment conditions were more sensitive to be resuspended.

\section{FUTURE CHALLENGES}

The following steps of the SEDUNIT Project will focus on the validation of the results obtained in the laboratory test in a real sewer catchment and the analysis of the existing sewer sediment transport models.

A field campaign is being developed in the metropolitan area of A Coruña in a series of pipelines with sediment accumulation problems. In these sections the sediment characteristics and the accumulation and erosion ratios are being measured and will be compared with the values obtained at Bens WWTP facility. The objective of this task is based on understanding the evolution and distribution of sediments in urban sewer systems. This knowledge would lead to better management practices and thus less maintenance procedures, which may cost from $300 € / \mathrm{km} /$ year to $10,000 € / \mathrm{km} /$ year in some particular cleaning activities [3], [15].

Concerning the in-sewer sediment transport models, different formulations are being revised in the literature in order to describe the sediment transport processes. Some authors reported reviews of the principal sediment transport equations applied in the field of sewer systems [4], [16], [17]. Classical formulas such as Meyer-Peter and Müller, Einstein Brown, 
van Rijn or Novak and Nalluri describe the bed transport of alluvial non-cohesive particles. In addition, Rouse, Einstein or van Rijn researches, among others, defined formulas for the transport of suspended sediments. Furthermore, there are some models such as AckersWhite, May or Velikanov that determine the total sediment transport. Some of these formulations are implemented in numerical codes, for example in Infoworks ICM software.

Most of these equations were developed using river sediments with a uniform distribution. This causes an important limitation in order to describe sewer sediments. The sediments that can be found in sewer systems present different origins and size classes. Thus, in-sewer processes such as the bed deposits cohesiveness or the erosion of the organic superficial layers could not be reproduced by many of these models. Some exceptions, for example the Skipworth model, derived from laboratory tests with synthetic cohesive particles [18]. This model associates the bed shear stress and the eroded bed height. Later, this model was modified after using the results of laboratory studies with organic and inorganic sediments [6]. More recent studies are focused on the erosion rate of cohesive and real sediments in a laboratory scale under different aeration conditions and accumulation periods [19]-[22].

The previous sediment transport models show that the bed shear stress is a key parameter in order to determine the volume of solids transported in sewer pipelines. Therefore, a methodology needs to be applied to obtain its value. For that, the shear stress contribution of the flow and the pipe contour should be considered [23]. Additionally, some studies included the contribution of the roughness introduced by the bed forms [7].

\section{CONCLUSIONS}

The SEDUNIT Project tried to advance knowledge of the sediment deposition inside the combined sewers. From the laboratory facility installed in a WWTP, different pipe geometries and experimental procedures were performed. First, an egg-shaped pipe was parallel tested with a commercial circular pipe with an equivalent area. The experiments performed suggest that the egg-shaped pipe presents a higher sediment transport capacity, due to the higher velocity and shear stress under low-flow conditions. As the combined sewer pipelines are subjected to dry weather conditions most of the time, the egg-shaped pipes become a solution in order to reduce the sediment accumulation. This kind of geometries are well-known for big collectors but the fabrication processes for small and plastic pipes is still under research.

The accumulation experiments in circular pipes of 315 and $400 \mathrm{~mm}$ outer diameters showed a linear accumulation within the first 7-11 days of accumulation. The accumulation rate was ranged from 1.4 and $3.8 \mathrm{~mm} / \mathrm{d}$. This quasi-constant evolution of the bed-deposits during the first days affects to the centreline velocity profiles. The velocity profiles were accelerated as the bed deposits increased, while the Reynolds shear stress kept constant. Furthermore, erosion tests were performed after a certain deposition period. Although the initial sediment height and flowrate conditions were identical in all cases, the eroded mass decreased as the consolidation time increased. The same trend was observed in the analysis of the organic content parameters from sediment samples taken before the erosion test beginning. Therefore, the erosion experiments proved that the bed strength is connected with the biological processes of the sediments.

The 'aging' of sediments is a parameter that should be included in the sediment transport models. The eroded mass and therefore the release of pollutant loads in the wastewater depend on this parameter. Classical formulations were derived from alluvial sediment experiments without considering cohesive particles. Current sewer sediment equations were calibrated from cohesive and non-cohesive particles experiments or from new approaches where the bed shear stress is the main parameter. Further steps in sewer sediments models 
should consider the evolution of the bed deposits properties in order to design new pipelines, maintenance strategies or estimate the impacts in the receiving media.

\section{ACKNOWLEDGEMENTS}

The SEDUNIT Project was supported by the MINECO and FEDER funding (Ref. CGL201569094-R). The construction of the flume test facility and part of the assistance in the experimental campaign was funded by the Projects OvalPipe I (Ref. ITC-20133052) and OvalPipe II (Ref. RTC-2016-4987-5) powered by the company ABN Pipe Systems S.L.U. and with the support of EMALCSA and EDAR Bens S.A. (MINECO/FEDER, EU). The research work of Mr. Juan Naves was financed by the Spanish Government grant (FPU14/01778).

\section{REFERENCES}

[1] Suarez, J., Puertas, J., Anta, J., Jácome, A. \& Álvarez-Campana, J.M., Gestión integrada de los recursos hídricos en el sistema agua urbana: Desarrollo Urbano Sensible al Agua como enfoque estratégico. Ingeniería Agua, 18, pp. 111-123, 2014.

[2] Suarez, J. \& Puertas, J., Determination of COD, BOD, and suspended solids loads during Combined Sewer Overflow (CSO) events in some combined catchments in Spain. Ecological Engineering, 24(3), pp. 199-217, 2005.

[3] Ashley, R., Bertrand-Krajewski, J.L., Hvitved-Jacobsen, T. \& Verbanck, M., Solids in sewers. Scientific \& Technical Report No. 14. IWA Publishing, London, UK, 2004.

[4] Bertrand-Krajewski, J.L., Modelling of Sewer Solids Production and Transport. Cours de DEA “Hydrologie Urbaine", Transport. INSA de Lyon, Lyon, France, 2006.

[5] Vollertsen, J. \& Hvitved-Jacobsen, T., Resuspension and oxygen uptake of sediments in combined sewers. Urban Water, 2(1), pp. 21-27, 2000.

[6] Rushforth, P.J., Tait, S.J. \& Saul, A.J., Modeling the erosion of mixtures of organic and granular in-sewer sediments. Journal of Hydraulic Engineering, 129(4), pp. 308315,2003 .

[7] Banasiak, R., \& Verhoeven, R., Transport of sand and partly cohesive sediments in a circular pipe run partially full. Journal of Hydraulic Engineering, 134(2), pp. 216-224, 2008.

[8] Seco, I., In-sewer organic sediment transport. Study of the release of sediments during wet-weather from combined sewer systems in the Mediterranean region in Spain. $\mathrm{PhD}$ thesis, UPC, Barcelona, Spain, 2014.

[9] Regueiro-Picallo, M., Naves, J., Anta, J., Puertas, J. \& Suárez, J., Experimental and numerical analysis of egg-shaped sewer pipes flow performance. Water, 8(12), pp. 587-596, 2016.

[10] Regueiro-Picallo, M., Naves, J., Anta, J., Suárez, J. \& Puertas, J., Monitoring accumulation sediment characteristics in full scale sewer physical model with urban wastewater. Water Science and Technology, 76(1), pp. 115-123, 2017.

[11] Regueiro-Picallo, M., Anta, J., Suárez, J., Puertas, J., Jácome, A. \& Naves, J., Characterization of sediments during transport of solids in circular sewer pipes. Water Science and Technology, in press, 2018.

[12] APHA, AWWA \& WEF, Standard Methods for the Examination of Water and Wastewater. 20th ed, American Public Health Association/American Water Works Association/Water Environment Federation, Washington DC, USA, 1998.

[13] ISO, ISO 2591-1:1988. Test Sieving - Part 1: Methods using test sieves of woven wire cloth and perforated metal plate. International Organization for Standardization, Geneva, Switzerland, 1988. 
[14] ISO, ISO 13320:2009. Particle size analysis. Laser diffraction methods. International Organization for Standardization, Geneva, Switzerland, 2009.

[15] Lange, R.L. \& Wichern, M., Sedimentation dynamics in combined sewer systems. Water Science and Technology, 68(4), pp. 756-762, 2013.

[16] De Sutter, R., Rushforth, P., Tait, S., Huygens, M., Verhoeven, R. \& Saul, A., Validation of existing bed load transport formulas using in-sewer sediment. Journal of Hydraulic Engineering, 129(4), pp. 325-333, 2003.

[17] Banasiak, R. \& Tait, S., The reliability of sediment transport predictions in sewers: influence of hydraulic and morphological uncertainties. Water Science and Technology, 57(9), pp. 1317-1327, 2008.

[18] Skipworth, P.J., Tait, S.J. \& Saul, A.J., Erosion of sediment beds in sewers: Model development. Journal of Environmental Engineering, 125(6), pp. 566-573, 1999.

[19] Tait, S.J., Marion, A. \& Camuffo, G., Effect of environmental conditions on the erosional resistance of cohesive sediment deposits in sewers. Water Science and Technology, 47(4), pp. 27-34, 2003.

[20] Banasiak, R., Verhoeven, R., De Sutter, R. \& Tait, S., The erosion behaviour of biologically active sewer sediment deposits: observations from a laboratory study. Water Research, 39(20), pp. 5221-5231, 2005.

[21] Schellart, A., et al., Detailed observation and measurement of sewer sediment erosion under aerobic and anaerobic conditions. Water Science and Technology, 52(3), pp. 137-146, 2005.

[22] Seco, I., Valentín, M. G., Schellart, A. \& Tait, S., Erosion resistance and behaviour of highly organic in-sewer sediment. Water Science and Technology, 69(3), pp. 672-679, 2014.

[23] Ackers, J., Butler, D. \& May, R.W.P., Design of sewers to control sediment problems. CIRIA. Report R141. Construction Industry Research and Information Association, London, UK, pp. 1-181, 1996. 